\title{
Application of Steel-Magnesium Hybrid Buckling Restrained Brace in Steel Power Plant Structure
}

\author{
Lin Song ${ }^{1, a}$, Dong Yinfeng ${ }^{1, b}$ \\ ${ }^{1}$ Key Laboratory of New Technology for Construction of Cities in Mountain Area (Chongqing \\ University), Ministry of Education, Chongqing, 400045, China \\ 2 School of Civil Engineering, Chongqing University, Chongqing 400045, China \\ a1554208307@qq.com, bdongyinfeng@cqu.edu.cn
}

\begin{abstract}
Keywords: Magnesium alloy BRB; Steel-Magnesium Hybrid BRB; power plant structure; seismic response

Abstract To improve seismic reduction and self-centering performance of buckling restrained braces (BRBs) placed in a steel power plant structure, magnesium alloy is used to completely or partly replace steel as the core material of BRBs. First, steel power plant structure models with BRBs using different core material are established respectively. Then, seismic response of these models is analyzed and compared. Results show that for steel structures placed with BRBs, their story shear force, displacement, plastic strength and residual deformation are quite different than the original one with common steel braces. Both magnesium alloy and steel-magnesium hybrid BRBs show better performance than steel BRB in reducing story drift and residual deformation. Moreover, for magnesium alloy and steel-magnesium hybrid BRBs, their merit of self-centering ability and energy dissipation are worthy for future research.
\end{abstract}

\section{Introduction}

Seismic performance of buckling-restrained braces (BRB) and its application in building structures have been widely studied ${ }^{[1,2,3,4]}$. In most studies, low-yielding-strength steel is adopted as core material for BRB. Although the study of BRB become more and more mature, application of $\mathrm{BRB}$ with other new core material and the corresponding design theory still need to be further developed.

Recently, magnesium alloy (Mg alloy) has been widely used in military, aviation, automobile and other fields for its light weight, high strength and high deformation ability ${ }^{[6,7]}$. However, $\mathrm{Mg}$ alloy used in civil engineering as building material is without precedent in recent research. Firstly, three types of BRBs are designed in the paper, i.e., one is steel BRB completely using low-yielding-strength steel as core material, for the other two BRBs the steel core material is completely or partly replaced with Mg alloy. Finally, the seismic response of steel power plant structures with above three types of BRBs placed are compared and discussed, which provides a basis for the wider application of $\mathrm{Mg}$ alloy BRB in building structures for the future.

\section{Power plant structure}

In this paper, a 600MW grade steel structure thermal power plant is selected as an example. There are 8 spans in longitudinal direction, the length of each span is $10 \mathrm{~m}$ and the total length is $80 \mathrm{~m}$. Besides there are 3 spans in transverse direction, the width of each span is $14 \mathrm{~m}, 8 \mathrm{~m}$ and $12 \mathrm{~m}$ respectively, the total width is $34 \mathrm{~m}$. For columns, beams, supports and other lateral components, the $\mathrm{Q} 345 \mathrm{~B}$ steel is used. The design lifetime of this structure is 50 years, the corresponding seismic 
fortification intensity is 8 , design basic peak acceleration is $0.2 \mathrm{~g}$, classification of design earthquakes is group 1, the basic wind pressure is $0.4 \mathrm{kN} / \mathrm{m}^{2}$ and the site category is III. The steel structure with common steel brace (original structure) is shown in Fig.1.

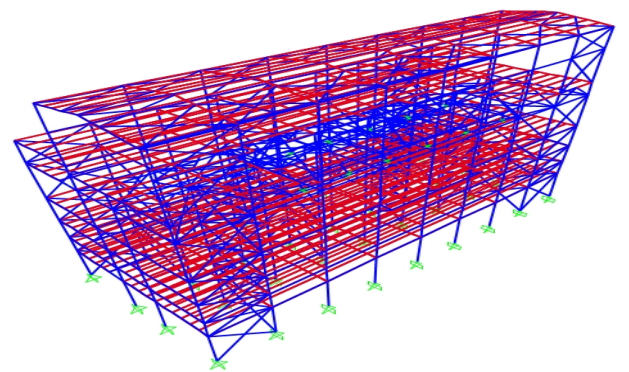

Fig.1 Original steel plant

\section{Parameters and configuration of BRBs}

In the paper, three types of BRBs are designed. One is steel BRB completely using low-yielding-strength steel as core material, for other two BRBs the Mg alloy is completely or partly core material which are named as $\mathrm{Mg}$ alloy BRB and steel-Mg hybrid BRB respectively. The core material of steel-Mg hybrid BRB is shown in Fig. 2 where $L_{0}$ represents the total length of the BRB, $L_{1}$ represents the length of steel segment, $L_{2}$ represents the length of $\mathrm{Mg}$ alloy at both ends of the core material. It is to be mentioned that the principle of these three types of brace used in the structure is stiffness equivalence.

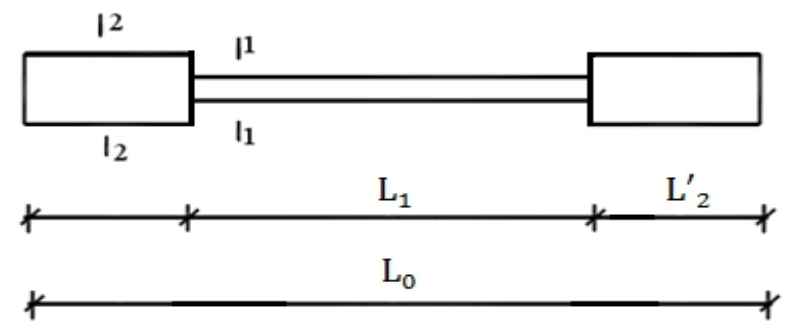

Fig.2 core material illustration of steel-Mg alloy BRB

According to the principle of stiffness equivalence, the geometrical and physical properties od BRBs are determined as shown in Table 1. Totally, eight BRBs are configured in the outside of first two floors and the location of them is shown in Fig. 3.

Table 1 Core material parameters of BRBs

\begin{tabular}{|c|c|c|c|}
\hline \multicolumn{2}{|c|}{ Specimen } & $\begin{array}{c}\text { Sectional area } \\
\left(\mathrm{mm}^{2}\right)\end{array}$ & $\begin{array}{c}\text { Length } \\
(\mathrm{mm})\end{array}$ \\
\hline \multicolumn{2}{|c|}{ Steel BRB } & 5000 & 14000 \\
\hline \multicolumn{2}{|c|}{ Mg-alloy BRB } & 22000 & 14000 \\
\hline \multirow{2}{*}{$\begin{array}{l}\text { Steel-Mg hybrid } \\
\text { BRB }\end{array}$} & Steel $\left(L_{1}\right)$ & 5000 & 12600 \\
\hline & $\operatorname{Mg}$ alloy $\left(L_{2}^{\prime}\right)$ & 8000 & 700 \\
\hline
\end{tabular}



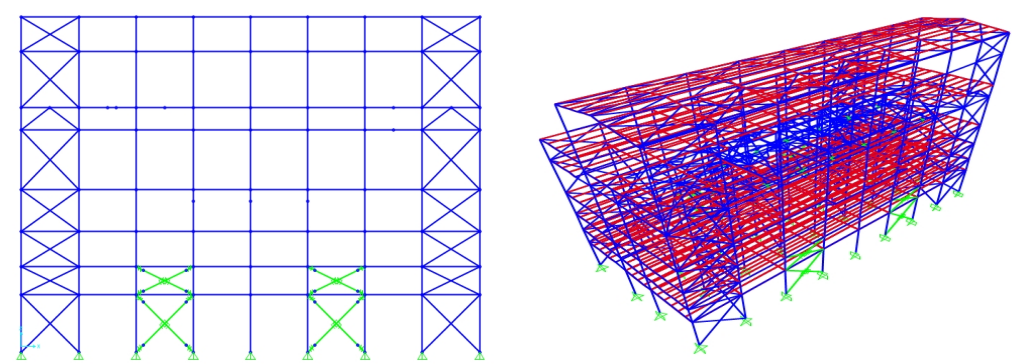

Fig. 3 The configuration of BRBs in the first two floors

\section{Cost comparison of BRBs}

Roughly, we compare the cost of core material of three types of BRBs. Firstly, the notions $\rho_{0,1}$, $A_{0,1}$ and $l_{0,1}$ respectively represent the density, sectional area and length of core materials. Their subscript 0 and 1 respectively represent that the core materials are steel and magnesium alloys. According to the data in the Table 1 , the mass $(M)$ the core materials, length $(l)$ and sectional area $(A)$ are shown in Eqs.1-5.

$$
\begin{aligned}
& M^{\text {steel }}=\rho_{0} \times A_{0} \times l_{0} \\
& M^{\text {Mgalloy }}=\rho_{1} \times A_{1} \times l_{1} \\
& M^{\text {Steel-Mgalloy }}=\rho_{0} \times A_{0} \times\left(0.9 \times l_{0}\right)+\rho_{1} \times\left(0.364 \times A_{1}\right) \times\left(0.1 \times l_{1}\right) \\
& l_{0}=l_{1} \\
& A_{0}=0.227 \times A_{1}
\end{aligned}
$$

The density relationship between steel and magnesium alloy is shown in Eq.6:

$$
\rho_{0}=4.76 \times \rho_{1}
$$

Using the data of Table 1 and above equations. In China, the price of steel is about $3000 ¥ /$ ton and magnesium alloy is about 4,500 $¥ /$ ton. According to material price and Eqs.1-6, it can be inferred that the core material cost of Mg alloy BRB is 1.5 times than the steel BRB, while the cost of Steel-Mg hybrid BRB is just $95 \%$ of steel BRB.

\section{Structure modal analysis}

It's easy to understand the basic performance parameters of a structure through modal analysis. The first three modes of the four structures are shown in Table 2. In general, such four structural modes are basically similar, so it is more effective to analyze and compare the structural energy dissipation performance of the three types of BRBs under earthquakes. 
Table2 Comparison of four structural modes

\begin{tabular}{cccccc}
\hline modal & $\begin{array}{c}\text { Original } \\
\text { structure }\end{array}$ & $\begin{array}{c}\text { Steel } \\
\text { BRB } \\
\text { structure }\end{array}$ & $\begin{array}{c}\text { Mg-alloy } \\
\text { BRB } \\
\text { structure }\end{array}$ & $\begin{array}{c}\text { Steel-Mg } \\
\text { hybrid BRB } \\
\text { structure }\end{array}$ \\
\hline frequency & 1 & 0.69 & 0.71 & 0.71 & 0.70 \\
(HZ) & 2 & 0.82 & 0.86 & 0.86 & 0.83 \\
& 3 & 0.84 & 0.90 & 0.90 & 0.84 \\
\hline
\end{tabular}

\section{Seismic performance}

Based on the code for seismic design of buildings in China (50011-2010 GB), an artificial ground motion named as ACC1 and two real ground motions respectively named as 000147xa and 12149360 are selected for analysis. Their time history curves of ground acceleration are given in Fig. 4 .
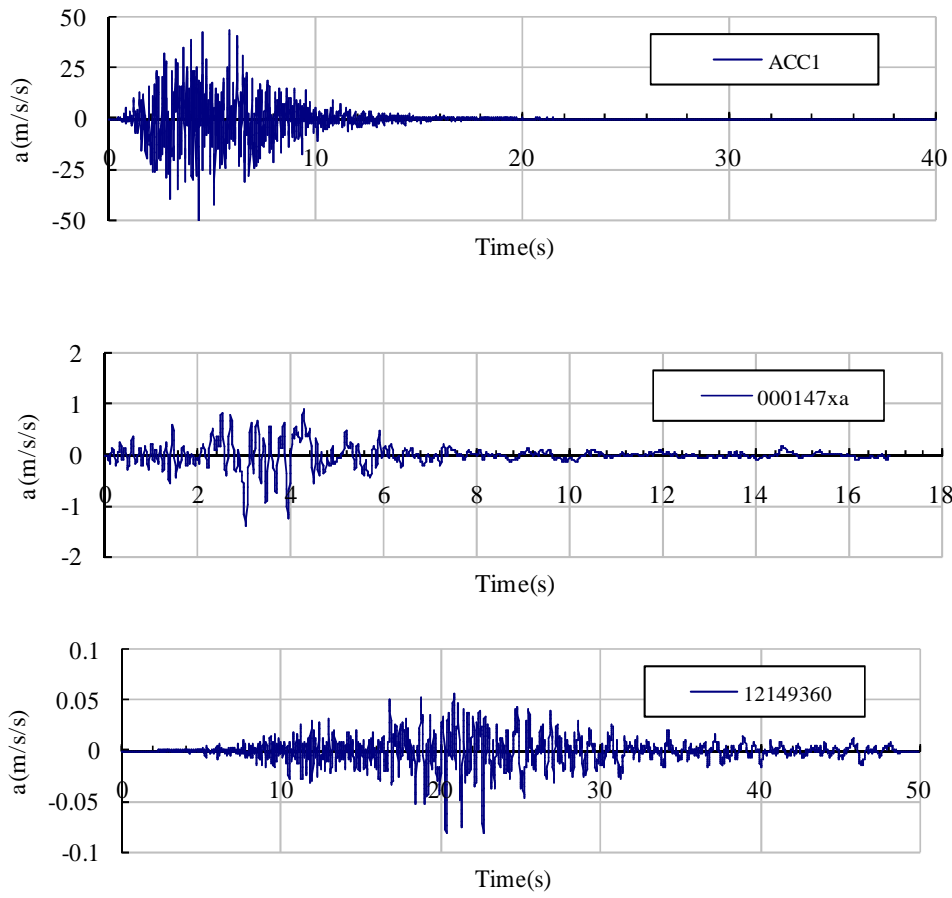

Fig.4 Seismic acceleration time history curve

\section{Story shear}

The envelope curves of story shear force corresponding to each structure under frequent earthquakes and rare earthquakes is shown in Fig.5. Under the action of frequent and rare earthquakes, the distribution of seismic action is uniform among each floor, the story shear force linearly increases from roof to ground, and its change rule for all the structures is basically similar. It shows that due to the configuration of BRBs, story shear force of structures with BRBs is slightly larger than that of the original one. The increase of story shear force for structure with $\mathrm{Mg}$-alloy BRBs is smaller than that with steel BRB and Steel-Mg hybrid BRB. 


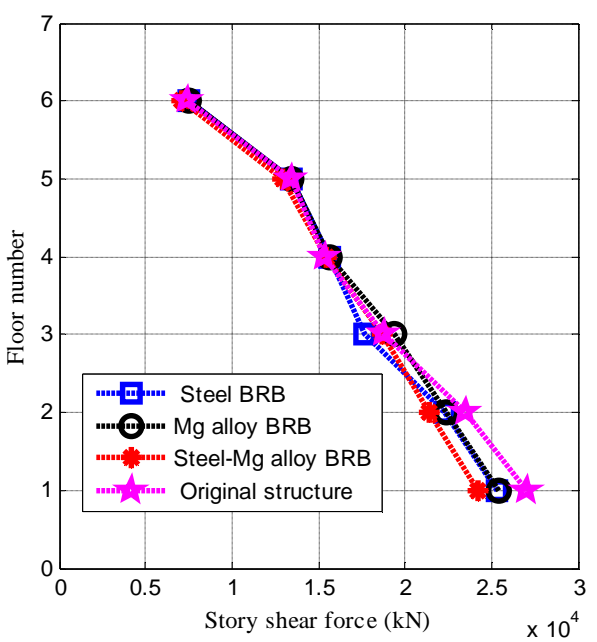

(a) Frequent earthquakes

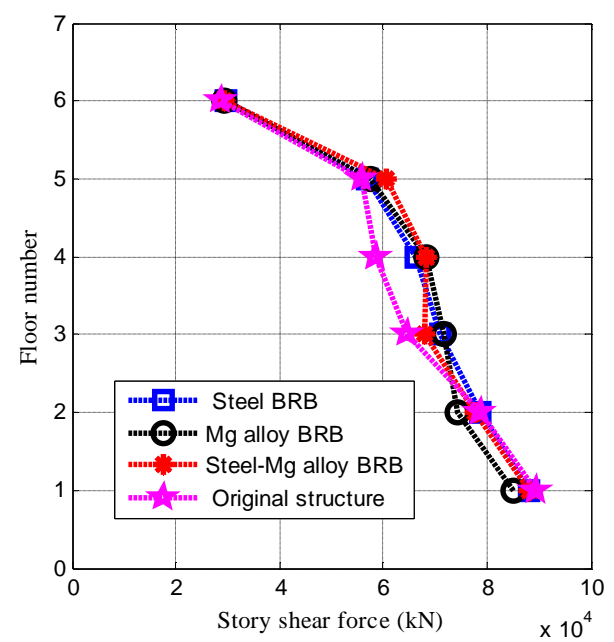

(b) Rare earthquakes

Fig.5 Story shear force under frequent and rare earthquakes

\section{Story drift angle}

Code for seismic design of buildings in China (50011-2010 GB) stipulates that the limit of the story drift angle for steel structures in elastic state is $1 / 250 \mathrm{rad}$. while for the steel structure in plastic state, the limit of the story drift angle is $1 / 50 \mathrm{rad}$. The envelope diagram of story drift angle under frequent and rare earthquakes is shown in Fig. 6.

Under frequent earthquakes, the story drift angle of all the structures meet the requirements of the code. For structures with BRBs, their change rule of story drift angle is similar among each floor, because the stiffness of BRBs are basically equal.

Under the rare earthquakes, it can be seen that the story drift angle of the original steel structure cannot meet the requirements of the code. In addition, the story drift angle of the structure with BRBs are obviously reduced. The story drift angle of the original structure in the first story can reach to 1/40 $\mathrm{rad}$. For structures with BRBs, their story drift angle can be reduced to 1/60 rad. In general, the story drift angle of structures with Mg alloy BRBs and Steel-Mg hybrid BRBs are smaller than that with steel BRBs.

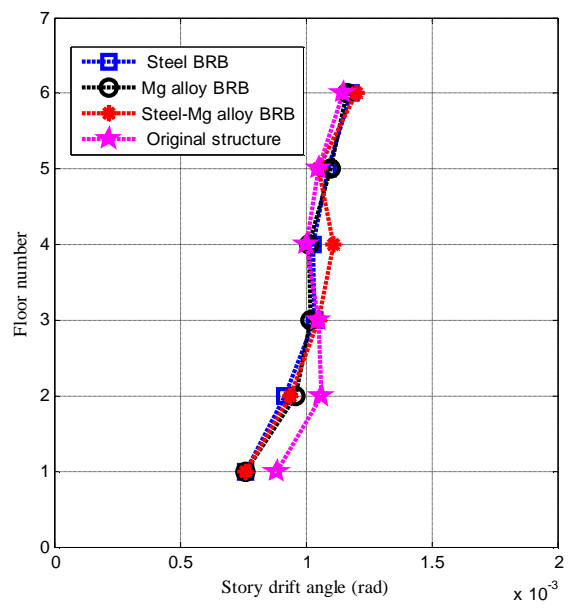

(a) Frequent earthquakes

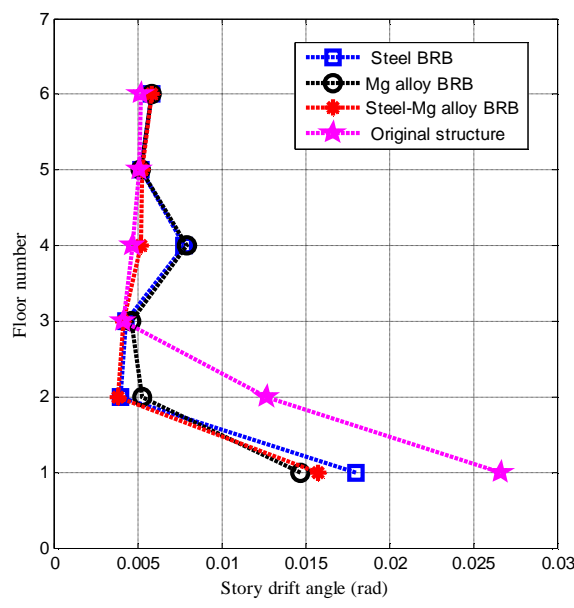

(b) Rare earthquakes

Fig.6 Maximum story drift angle under frequent and rare earthquakes

\section{Displacement time history}

The displacement time history of the upper node of column in the bottom of structure under the ground motion is used as an example to compare the displacement change with and without BRBs.The position of the column is shown in Fig.7. 


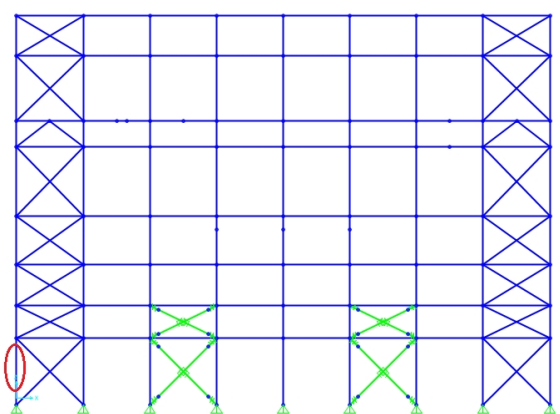

Fig.7 The location of Column for time history analysis

It can be seen from the Fig. 8 the BRBs can efficiently reduce the residual deformation of structures under rare earthquakes. Under rare earthquakes, the residual deformation of the original structure is $106.6 \mathrm{~mm}, 15.9 \mathrm{~mm}$ for the structure with steel BRBs, $5.2 \mathrm{~mm}$ for the structure with steel-Mg hybrid BRBs and $1.7 \mathrm{~mm}$ for the structure with $\mathrm{Mg}$ alloy BRBs. For the structure with $\mathrm{Mg}$ alloy BRBs, its residual deformation is much less than that of the other three structures. Therefore, the $\mathrm{Mg}$ alloy BRB performances best in self-centering and seismic reduction.

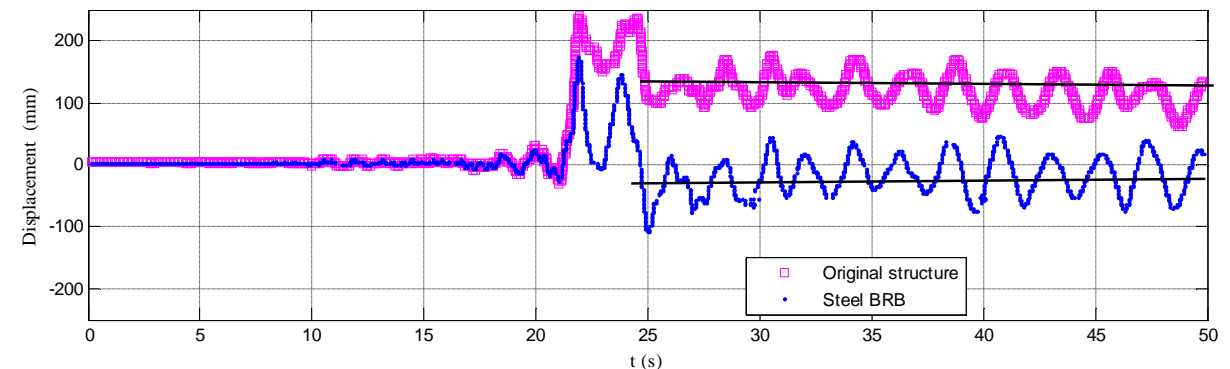

(a) Original structure and steel BRB structure

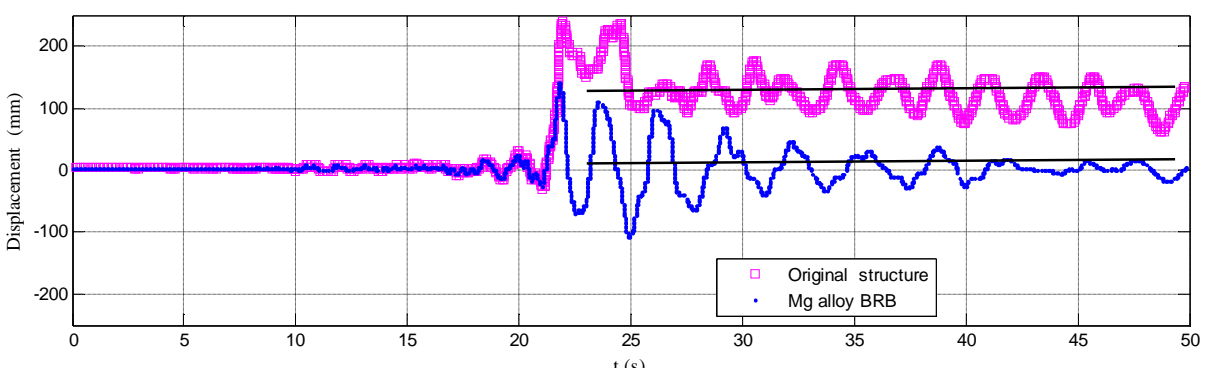

(b) Original structure and $\mathrm{Mg}$ alloy brace structure

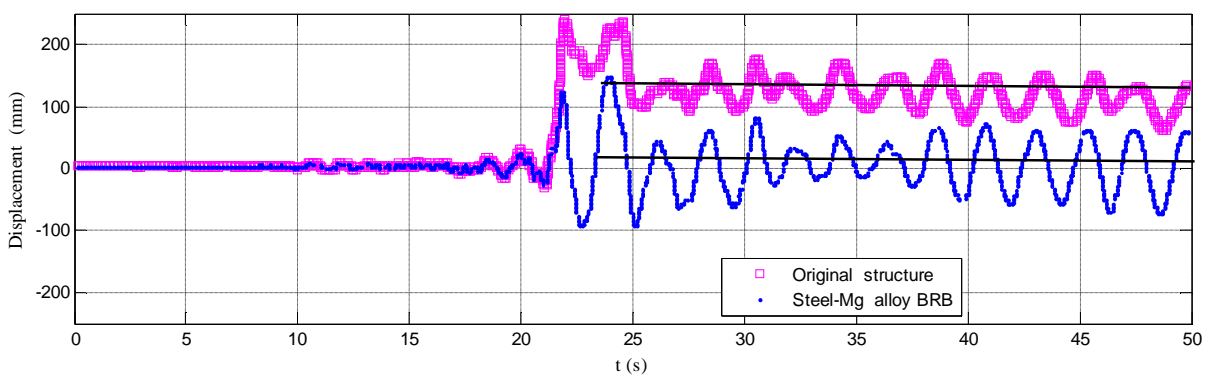

(c) Original structure and Steel-Mg Hybrid brace structure

Fig.8 Displacement of the upper joint of a corner column under rare earthquake

\section{Hysteresis performance}

For steel and Steel-Mg hybrid BRBs, their hysteresis curve under different ground motion are shown in Fig. 9. The energy dissipation of steel- Mg hybrid BRB is $92.1 \% \sim 94.6 \%$ of the steel BRB. It can be inferred that such two BRBs have similar energy dissipation performance. 

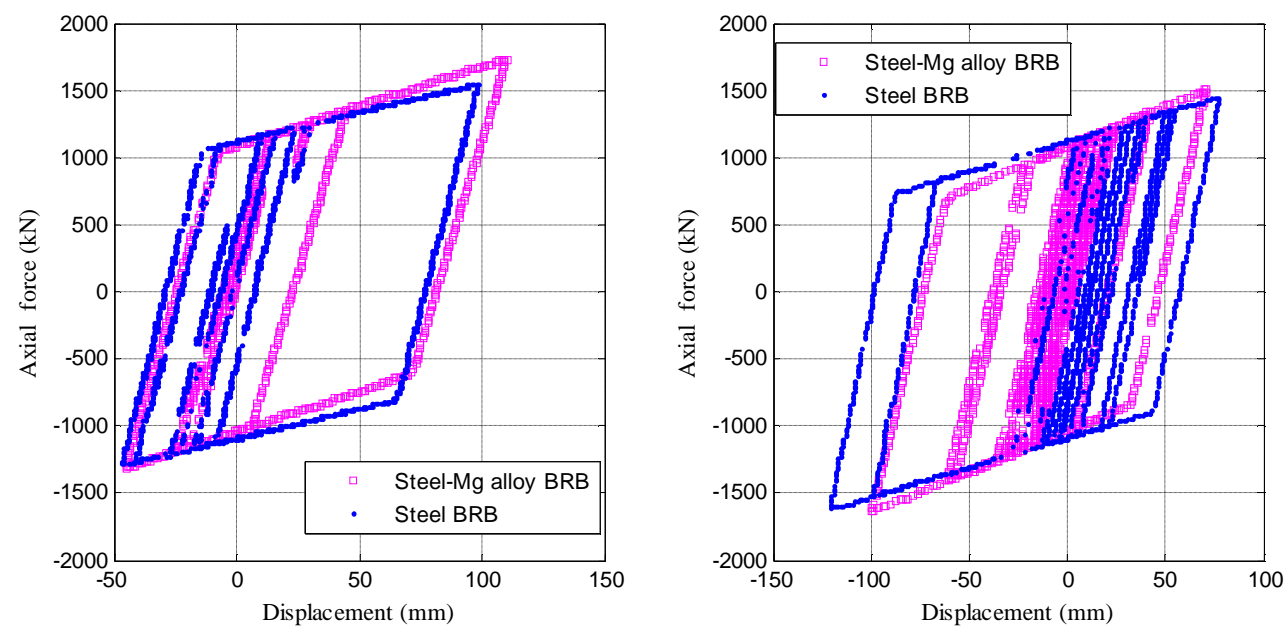

Fig.9 Hysteresis curve of Steel BRB and Steel-Mg Hybrid BRB

\section{Conclusions}

Steel structure models with three types of BRBs are established to analysis their seismic response under frequent and rare earthquakes in the paper. The main conclusions are as follows:

1. All BRBs cause slight increase in structural story shear force, but the increase of shear force for structure with $\mathrm{Mg}$ alloy BRBs is much smaller than that with steel BRBs

2. All BRBs have an obvious impact on story displacement and residual deformation in steel structure. Mg-alloy BRB have a better performance than steel BRB in reducing story drift and residual deformation.

3. For Mg alloy and Steel-Mg hybrid BRBs, their self-centering ability is perfect due to high strength and good elasticity.

4. Steel-Mg hybrid BRB combines the advantages of steel and $\mathrm{Mg}$ alloy BRB and its material cost is cheaper than Steel and Mg alloy BRBs, therefore its application in steel structures is recommended.

\section{References}

[1] Cameron J B, Nicos M, Ian D A. Component testing seismic evaluation and characterization of buckling-restrained braces [J]. Journal of Structural Engineering, ASCE, 2004, 130(6): 880-894.

[2] Chen Zhengcheng. Behavior and application of buckling inhibited braces with steel lateral support elements(I) [J]. Progress in Steal Building Structures, 2005, 7(5): 29-35.

[3] Eryasar M E, Topkaya C. An experimental study on steel-encased buckling-restrained brace hysteretic dampers [J]. Earthquake Engineering and Structural Dynamics, 2010, 39(5):561-581.

[4] Usami T, Lu Z H, Ge H B. A seismic upgrading method for steel arch bridges using buckling-restrained

braces [J]. Earthquake Engineering and Structural Dynamics,2005,34( 4 /5) : 471-496.

[5] ASM International, Magnesium and Magnesium Alloy [M]. OH: Metal Park, 1999

[6] Kojima Y. Platform science and technology for advanced magnesium alloy [J]. Mater. Sci. Forum, 2000, 350 351: 3-12 